\title{
Information exchange using a prescribed form and involvement of occupational health nurses promotes occupational physicians to collaborate with attending physicians for supporting workers with illness in Japan
}

\author{
Go MUTO ${ }^{1,2 * a}$, Rina ISHII-NAKAMURA ${ }^{1 \mathrm{a}}$, Kazuhito YOKOYAMA ${ }^{1 *}$, \\ Fumihiko KITAMURA ${ }^{1}$, Yuki OMORI ${ }^{3}$, Masahiko SAITO ${ }^{4}$ and Motoki ENDO ${ }^{5,6}$ \\ ${ }^{1}$ Department of Epidemiology and Environmental Health, Juntendo University Faculty of Medicine, Japan \\ ${ }^{2}$ Department of Global Health and Population, Harvard T.H. Chan School of Public Health, USA \\ ${ }^{3}$ Department of Hygiene, Kitasato University School of Medicine, Japan \\ ${ }^{4}$ Hoshizaki Clinic of Daido Steel Co., Japan \\ ${ }^{5}$ Department of Public Health, Tokyo Women's Medical University, Japan \\ ${ }^{6}$ Department of Public Health, Juntendo University Faculty of Medicine, Japan
}

Received August 3, 2017 and accepted December 11, 2017

Published online in J-STAGE December 19, 2017

\begin{abstract}
The maintenance of a balance between work and disease treatment is an important issue in Japan. This study explored factors that affect collaboration between occupational physicians (OPs) and attending physicians (APs). A questionnaire was mailed to 1,102 OPs. The questionnaire assessed the demographic characteristics of OPs; their opinions and behaviors related to collaboration, including the exchange of medical information with APs; and the occupational health service system at their establishments. In total, 275 OPs completed the questionnaire (25.0\% response rate). Over $80 \%$ of respondents believed OPs should collaborate with APs. After adjusting for company size, collaboration $\geq 10$ times/yr (with regard to both returning to work following sick leave and annual health check-ups for employees) was significantly associated with environmental factors, such as the presence of occupational health nurses (odds ratio (OR): 5.56 and 5.01, respectively, $p<0.05$ ) and the use of prescribed forms for information exchange (OR: 4.21 and 3.63, respectively, $p<0.05$ ) but not with the demographic characteristics of the OPs ( $p>0.05)$. The majority of OPs believed that collaboration with APs is important for supporting workers with illnesses. Support systems including prescribed forms of information exchange and occupational health nurses, play pivotal roles in promoting this collaboration.
\end{abstract}

Key words: Occupational physicians, Occupational health nurses, Collaboration, Information exchange, Balance between work and disease treatment, Return-to-work, Follow-up of annual health check-ups

\footnotetext{
${ }^{a}$ These authors have contributed equally to this work.

*To whom correspondence should be addressed.

Introduction 
and disease treatment has become a major social issue in Japan because of the aging labor force and low birth rate ${ }^{1-5)}$. Collaboration between attending physicians (APs) and occupational physicians (OPs) is important for supporting workers with mental and/or physical illnesses ${ }^{3-6)}$. In 2016, the Japanese Government and the Ministry of Health, Labour, and Welfare of Japan published guidelines for balancing work and disease treatment in the workplace $^{6}$. According to these guidelines, collaboration between OPs and APs through employee-approved medical information exchange is important.

Such collaboration has two major goals: to ensure that treatment is accessible to employees and to allow employees to continue working despite their illness ${ }^{6-11)}$. The former goal includes providing educational support to workers with non-communicable diseases, such as diabetes, helping them adhere to treatment recommendations, and preventing future complications ${ }^{6-9)}$. The Clinical Guide for Diabetes issued by the Japan Diabetes Society $(2016)^{9)}$ recommends collaboration between APs (diabetes specialists) and OPs. The latter goal includes supporting the return to work of patients with chronic diseases, such as cancer, mental health disorders, and stroke ${ }^{3-6,10,11)}$. One of the integral roles of OPs are the assessment and management for employees' fitness for work in order to identify any difficulties resulting from diseases suffered, which could occur when workers hope to return to work $^{12-14)}$. OPs play indispensable roles in evaluating the fitness for work for specific tasks, ensuring a satisfactory fitness between workers and their jobs, and enabling them to undertake their work safely and effectively. In this context, exchanging information on workers' health condition is essential for OPs, and collaboration between OPs and APs is one of the most important support systems for employees on sick leave who want to return to work ${ }^{11-18)}$. Information provided by APs is beneficial to OPs and allows them to adjust workplace environments according to the employee's specific needs and disabilities ${ }^{10-15}$.

The importance of collaboration between OPs and APs has been highlighted in European countries, where primary healthcare and occupational health are integrated ${ }^{19-28)}$. In 2010, the United Kingdom implemented the Statement of Fitness for Work (Fit Note $)^{29)}$, which stipulates that general practitioners (GPs) provide support to workers who wish to return to work following sick leave; its focus is on facilitating the integration of their diseases or disabilities into their work ${ }^{30-32)}$. Based on a survey in the United Kingdom, GPs showed low levels of interest in collaboration, possibly due to a lack of knowledge or confidence $^{31)}$. However, a past study from France noted that the majority of GPs had positive opinions regarding collaboration ${ }^{19)}$. Therefore, several educational workshops have been implemented to help GPs achieve ideal outcomes from the Fit Note ${ }^{33-36)}$.

Collaboration between OPs and APs is most effective for the purpose of early returning to work as well as for preventing non-communicable diseases ${ }^{15-18,37)}$. Several European studies explored the impact of collaboration on early return to work in patients with cancer ${ }^{15)}$, mental disorders ${ }^{16)}$, and musculoskeletal disorders ${ }^{17,}{ }^{18)}$. Three randomized control trials (RCTs) on mental disorders and orthopedic diseases demonstrated the effectiveness of collaboration for shortening the illness-related absence period ${ }^{16-18)}$. However, one RCT evaluating female cancers did not show a significant benefit, which may be explained by the small sample size ${ }^{15}$. From the perspectives from an article in Japan, multifaceted interventions including collaboration improved adherence to diabetes treatment recommendations ${ }^{37)}$. Based on these results, collaboration between OPs and APs is highly recommended in the Clinical Guide for Diabetes formulated by the Japan Diabetes Society $(2016)^{9)}$. However, several studies have shown that current models of collaboration

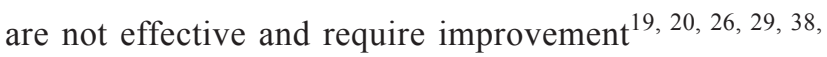
40). Specific barriers may explain this ineffectiveness; for example, APs may have a poor understanding of OP roles, or support measures may be insufficient for APs and $\mathrm{OPs}^{5}$, 19, 39, 40). Support systems for APs, including an educational introduction to Fit Note and access to medical social workers, are known to promote collaborative behavior $^{5,34,36,39-41)}$. However, although a past report showed that occupational health nurses play a supportive role for OPs with respect to health promotion activities at Japanese worksites, it remains unclear whether similar support systems facilitate collaborative behavior by $\mathrm{OPs}^{42)}$. Based on these studies, we formulated the following hypotheses. First, collaborative attitudes on the parts of OPs may be associated with supportive measures, such as the involvement of occupational health nurses and information exchange. Second, these measures may be independent of the size of worksites or the demographic characteristics of the OPs.

The primary objective of this cross-sectional study was to determine how support systems and other factors affect OP collaborative behavior toward APs. Additionally, we explored whether guidelines, which may be also useful at small worksites, promoted communication and encouraged collaboration between APs and OPs. Therefore, the 
Table 1. Characteristics of 275 occupational physicians

\begin{tabular}{lr}
\hline & $\mathrm{n}(\%)$ \\
\hline Gender & \\
$\quad$ Male & $208(75.6)$ \\
$\quad$ Female & $67(24.4)$ \\
Experience as a medical doctor (yr) & \\
$\leq 10$ & $29(10.7)$ \\
$11-20$ & $71(26.1)$ \\
$21-30$ & $92(33.8)$ \\
$>30$ & $80(29.4)$ \\
Experience as an occupational physician (yr) & \\
$\leq 10$ & $119(43.5)$ \\
$11-20$ & $89(32.5)$ \\
$21-30$ & $53(19.3)$ \\
$>30$ & $13(4.7)$ \\
Certification of specialist in occupational medicine & \\
Senior Occupational Health Physician certified by Japan Society for Occupational Health & $77(28.0)$ \\
Occupational Health Physician certified by Japan Society for Occupational Health & $93(33.8)$ \\
Occupational Health Consultant certified by Ministry of Health, Labour, and Welfare of Japan & $150(54.5)$ \\
None & $85(30.9)$ \\
Certification of specialist in clinical medicine & \\
Internal medicine & $70(25.5)$ \\
Surgery & $32(11.6)$ \\
Others & $30(10.9)$ \\
None & $147(53.5)$ \\
Full-time & $105(38.2)$ \\
Part-time & $150(54.5)$ \\
Retired & $25(9.1)$ \\
\hline & \\
\hline & \\
\hline & \\
\hline & \\
& \\
&
\end{tabular}

aims of this study is to identify factors that may affect collaboration between OPs and APs.

\section{Subjects and Methods}

\section{Data collection}

An anonymous questionnaire was mailed to 1,102 all the members of the Expert Community of Occupational Health Physicians of the Japan Society for Occupational Health in November 2015. This society is the largest academic organization of occupational medicine in Japan and the members of its expert community of occupational health physicians are professionals including full-time occupational physicians, part-time occupational physicians whose specialty is occupational medicine, and occupational medicine researchers working as part-time occupational physicians. Therefore, this cohort depicts the opinions and behavior of professional occupational physicians in Japan. The questionnaire focused on opinions and behaviors related to collaboration, including the exchange of medical information, between OPs and APs as well as on corporate occupational health service systems.

Questions addressed the demographic characteristic of OPs, and eight items solicited their opinions toward collaboration with APs (Table 2) in the service of supporting employees' return to work following sick leave, preventing diseases, and facilitating collaboration. Each question relied on a four-point Likert scale consisting of 'strongly agree,' 'agree,' 'disagree,' and 'strongly disagree.'

The questionnaire also addressed the OPs' workplaces and support measures (Table 3), including company size, the presence of occupational health nurses, and the circumstances under which companies require OPs to collaborate with APs. Furthermore, in order to evaluate the behaviour of collaboration with APs, the frequencies of collaboration was examined under the situation of their return-to-work and of examining their annual health check-ups. Collaboration and/or medical information exchange was defined as the exchange of documents or face-to-face/telephone communication about vari- 
Table 2. Opinions of 275 occupational physicians (OPs) for collaboration with attending physicians (APs) to support employees for balancing work and disease treatment

\begin{tabular}{|c|c|c|c|c|c|c|}
\hline & Items & $\begin{array}{l}\text { Strongly } \\
\text { agree }\end{array}$ & Agree & Disagree & $\begin{array}{l}\text { Strongly } \\
\text { disagree }\end{array}$ & $\begin{array}{c}\text { No } \\
\text { answers }\end{array}$ \\
\hline (ii) & $\begin{array}{l}\text { OPs should collaborate with employees' APs for supporting their return-to-work } \\
\text { after sick leave due to chronic physical diseases. }\end{array}$ & $163(59.3)$ & $96(34.9)$ & $15(5.5)$ & $0(0.0)$ & 1 \\
\hline (iii) & $\begin{array}{l}\text { OPs should collaborate with employees' APs with regard to the support of } \\
\text { prevention of their diseases exacerbation. }\end{array}$ & $146(53.1)$ & $114(41.5)$ & $13(4.7)$ & $1(0.4)$ & 1 \\
\hline (iv) & $\begin{array}{l}\text { OPs should collaborate with employees' APs with regard to support and } \\
\text { preparation for their sudden attacks of diseases in case of emergency. }\end{array}$ & $200(72.7)$ & $68(24.7)$ & $6(2.2)$ & $0(0.0)$ & 1 \\
\hline (v) & $\begin{array}{l}\text { OPs should share drug information of employees with their APs toward } \\
\text { improving effectiveness of treating chronic diseases. }\end{array}$ & $124(45.1)$ & $116(42.2)$ & $30(10.9)$ & $4(1.5)$ & 1 \\
\hline (vi) & $\begin{array}{l}\text { Occupational nurses and other staffs play important roles when OPs want } \\
\text { to collaborate with employees' APs. }\end{array}$ & $160(58.2)$ & $92(33.5)$ & $20(7.3)$ & $2(0.7)$ & 1 \\
\hline (vii) & $\begin{array}{l}\text { It is important for OPs to know several physicians at medical institutions around } \\
\text { OPs' companies and to build good relationships with them in advance. }\end{array}$ & $133(48.4)$ & $110(40.0)$ & $26(9.5)$ & $4(1.5)$ & 2 \\
\hline (viii) & $\begin{array}{l}\text { Providing compensation to APs for collaboration with OPs of patients' } \\
\text { workplaces by national health care service system would promote this development. }\end{array}$ & $94(34.2)$ & $100(36.4)$ & $68(24.7)$ & $11(4.0)$ & 2 \\
\hline
\end{tabular}

Number $(\%)$

ous topics, including employees' medical conditions, medications, and plans for treatment or return to work. Since many OPs, especially part-time OPs may work for several companies at the same time in Japan, we instructed respondents of the questionnaire to select one specific workplace at their wills and answer all the other questions in the same specific workplace such as the presence of occupational health nurses or prescribed forms for collaboration. Based on this instruction, respondents of this questionnaire answered actual collaborative times of information exchange with employees' APs per year, which enabled us to analyze collaborative behavior and its related supportive factors precisely. The Research Ethics Committee for the Faculty of Medicine at Juntendo University approved this study (No.2015076). All the participants of this study were informed and consent on documents to the purposes of the research.

\section{Statistical data analysis}

To examine the factors affecting the annual frequency of collaboration between OPs and APs, answers submitted by retired OPs were excluded from the statistical analyses (Tables 3 and 4). We divided respondents into two groups according to the presence or absence of several factors and compared the difference in the frequency of collaboration between the two groups using a t-test. Logistic regression analysis was also used to calculate the odds ratios (ORs) with confidence intervals (CIs) for collaboration with APs more than or equal to 10 times per year. We set the cutoff value as 10 because the average and stan- dard deviation of the distribution of collaboration times a year in returning-to-work was 9.2 and 10.1 respectively, and in health check-ups they were 12.5 and 11.7 respectively. In this analysis, the values of the odds ratios were adjusted for company size, and the data were converted into a binomial format depending on the number of employees $(>500$ employees $=1$ and $<500=0)$. Our rationale for this approach was that larger companies, with more than 1,000 workers, generally have occupational health support due to legal requirement in Japan ${ }^{34,35)}$, which may be a confounding factor. From our database, the percentages of the presence of occupational health nurses in small and large sized companies were $48.9 \%$ and $95.6 \%$ respectively if the cutoff value was 500 , while they were $63.4 \%$ and $96.6 \%$ respectively if the cutoff value was 1,000 . Therefore, we set the cutoff value was to be 500 in order to highlight the influence by the difference of presence or absence of supportive system. OP experience was converted into a binomial value $(>10 \mathrm{yr}=1$ and $<10 \mathrm{yr}=0)$. As for opinions about collaboration, answers as 'strongly agree' were compared to other answers in order to contrast OPs ideas more clearly. Analyses were performed IBM SPSS Statistics 22.

\section{Results}

In total, 275 OPs completed the questionnaire (response rate of $25.0 \%$ ). Table 1 presents participants' characteristics about their personal and professional information. Males accounted for three-quarters of the respondents. 
G MUTO et al.

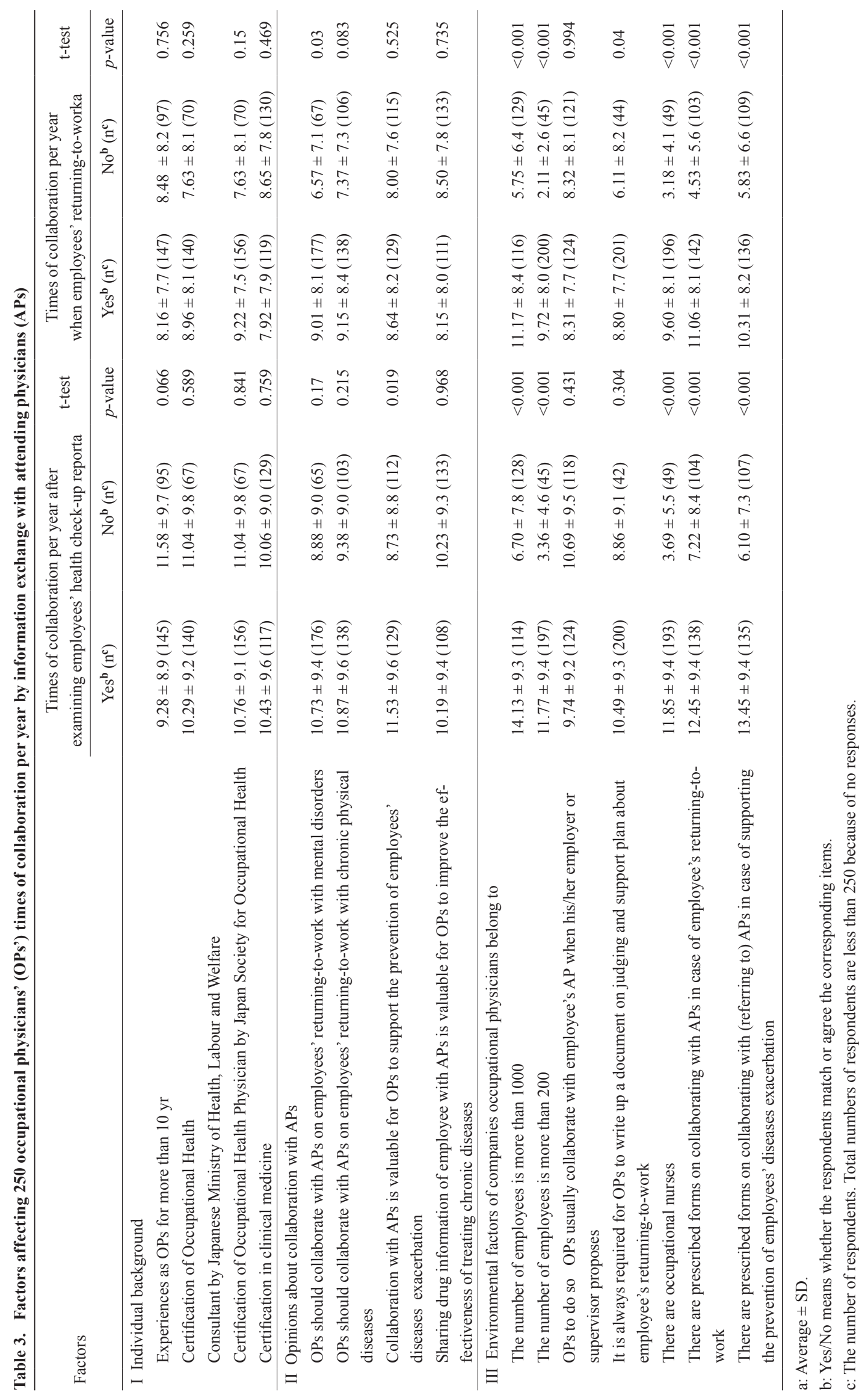


The most common length of experience for medical physicians was $21-30 \mathrm{yr}$, followed by $>30 \mathrm{yr}$. The length of experience among OPs was most commonly $\leq 10 \mathrm{yr}$, followed by $11-20 \mathrm{yr}$. Approximately $60 \%$ of respondents were Occupational Health Physicians certified by Japan Society for Occupational Health. Additionally, approximately $55 \%$ of respondents were certified as Occupational Health Consultants through the Ministry of Health, Labour, and Welfare of Japan, while approximately 30\% of respondents lacked either certification. The questionnaire revealed that $48 \%$ of participants were certified as Clinical Medicine specialists (Internal Medicine, 25.5\%; Surgery, $11.6 \%$ ), whereas $54 \%$ of participants were not. Additionally, we found that the OP respondents predominantly worked part-time; this was followed by those who worked full-time or were retired.

Table 2 shows the responses from 275 OPs regarding collaboration with APs to support and enable employees to maintain a balance between work and disease treatment. The majority of OPs had affirmative opinions regarding the necessity and value of collaboration with APs in several situations, including the return to work following sick leave and the prevention of disease exacerbation. Furthermore, approximately $90 \%$ of respondents had positive views about the importance of occupational health nurses and other occupational health staff members and valued the development of strong relationships with APs. Most respondents believed that APs would be more likely to collaborate with OPs if the National Health Care Service Systems provided compensation.

To increase our understanding of the dynamics of collaboration between OPs and APs, the number of collaborations per year and affecting several factors were analyzed as shown in Table 3. This enabled us to compare the tendency of collaboration behavior between different groups of OPs. We hypothesized that collaboration was influenced by the individual backgrounds of OPs, such as their length of experience as an OP and whether they had a specialization in Occupational or Clinical Medicine. However, the specific demographic characteristics of the OPs were not associated with the frequency of collaboration. Respondents who strongly agreed with the importance of collaboration between APs and OPs regarding workers returning to work following leave for mental health disorders and with the usefulness of collaboration to prevent exacerbation of diseases collaborated more frequently. On the other hand, strongly positive opinions regarding the importance of collaboration about individuals returning to work following a physical disease and the usefulness of collaboration for improving the effectiveness of treatment were not associated with collaboration frequency. Additionally, most support measures for OPs at companies were significantly associated with the frequency of collaboration. These support measures included the size of the company, the involvement of occupational health nurses, and the presence of specific prescribed forms for collaborating in cases of employees returning to work following sick leave and preventing disease exacerbation. However, we found that company-mandated APOP collaboration did not result in more collaboration than that did the absence of such mandates.

In order to adjust for company size, which can be a confounding factor against collaboration frequency, we used a logistic regression model. Table 4 shows the adjusted odds ratios (ORs) with $95 \%$ confidence intervals (CIs) for collaborating (i.e., information exchange) at least 10 times per year about employees returning to work following sick leave and about annual health checkups. We observed a significant relationship between the frequency of collaboration between OPs and APs and the former's positive opinions about the importance of collaboration for employees returning to work with mental health disorders and/or physical diseases (OR: 2.43, 95\% CI: $1.19-4.95$; OR: 2.23 , 95\% CI: $1.21-4.12$, respectively). In terms of collaboration about annual health check-ups, there were also significant associations between the frequency of collaboration and the OPs' positive opinions regarding the importance of collaboration to prevent disease exacerbation and to establish a good relationship with APs (OR, 2.04, 95\% CI: 1.14-3.65; OR, $1.89,95 \%$ CI: 1.06-3.36, respectively). Surprisingly, several environmental factors (e.g., support for OPs) had a stronger effect on collaboration than did the factors discussed previously. Collaboration related to returning to work was significantly associated with the presence of occupational health nurses and the presence of prescribed forms for collaboration about returning to work (OR: 5.56, 95\% CI: 1.20-25.8; OR: 4.24, 95\% CI: 2.01-8.82, respectively). Collaboration during annual health check-ups was also significantly related to the presence of occupational health nurses and the presence of prescribed forms for collaboration to support disease prevention or exacerbation (OR: 5.01, 95\% CI: 1.37-18.3; OR: 3.63, 95\% CI: 1.94-6.79, respectively). By contrast, other factors (e.g., the backgrounds of OPs) were not associated with collaboration. As shown above, environmental factors, such as the involvement of occupational health nurses and guidelines including prescribed forms for collaboration, 
Table 4. Adjusted odds ratios (ORs) with $95 \%$ confidence intervals (CI) for collaboration (information exchange) with attending physicians (APs) $\geq 10$ times/yr among 250 occupational physicians (OPs) analyzed by logistic regression model

\begin{tabular}{|c|c|c|}
\hline & Returning-to-work & $\begin{array}{l}\text { Follow-up of annual } \\
\text { health check-ups }\end{array}$ \\
\hline & ORs $(95 \% \mathrm{CI})$ & ORs $(95 \% \mathrm{CI})$ \\
\hline \multicolumn{3}{|l|}{ I Individual background } \\
\hline \multicolumn{3}{|l|}{ OPs are male } \\
\hline Experiences as OPs for $\geq 10 \mathrm{yr}$ & $0.83(0.46-1.51)$ & $1.60(0.90-2.84)$ \\
\hline Certification of Occupational Health Consultant by Japanese Ministry of Health, Labour and Welfare & $1.65(0.90-3.00)$ & $0.88(0.49-1.55)$ \\
\hline Certification in clinical medicine & $0.72(0.40-1.31)$ & $1.11(0.63-1.95)$ \\
\hline \multicolumn{3}{|l|}{ II Opinions about collaboration with APs } \\
\hline OPs should collaborate with APs on employees' returning-to-work with mental disorders & $2.43(1.19-4.95)$ & $1.78(0.93-3.41)$ \\
\hline OPs should collaborate with APs on employees' returning-to-work with chronic physical diseases & $2.23(1.21-4.12)$ & $1.58(0.88-2.82)$ \\
\hline $\begin{array}{l}\text { Collaboration with APs is valuable for OPs to support the prevention of employees' diseases exacer- } \\
\text { bation }\end{array}$ & $1.47(0.82-2.66)$ & $2.04(1.14-3.65)$ \\
\hline $\begin{array}{l}\text { Sharing drug information of employee with APs is valuable for OPs to improve the effectiveness of } \\
\text { treating chronic diseases. }\end{array}$ & $0.82(0.45-1.47)$ & $1.00(0.57-1.77)$ \\
\hline $\begin{array}{l}\text { It is important for OPs to know several physicians at medical institutions } \\
\text { around OPs' companies and to build good relationships with them in advance }\end{array}$ & $1.71(0.95-3.09)$ & $1.90(1.06-3.36)$ \\
\hline $\begin{array}{l}\text { Providing compensation to APs for collaboration with OPs of patients' workplaces by national health } \\
\text { care service system would promote this development. }\end{array}$ & $0.65(0.35-1.22)$ & $0.94(0.52-1.71)$ \\
\hline \multicolumn{3}{|l|}{ III Environment of companies where OPs are working } \\
\hline $\begin{array}{l}\text { It is always required for OPs to write up a document on judging and support plan about employee's } \\
\text { returning-to-work }\end{array}$ & $1.04(0.46-2.39)$ & $0.65(0.29-1.45)$ \\
\hline OPs usually collaborate with employee's AP when his/her employer or supervisor proposes OPs to do so & $0.85(0.48-1.53)$ & $0.75(0.43-1.32)$ \\
\hline There are occupational nurses & $5.56(1.20-25.8)$ & $5.01(1.37-18.3)$ \\
\hline There are prepared forms documents on collaborating with APs in case of employee's returning-to-work & $4.21(2.01-8.82)$ & $1.64(0.88-3.04)$ \\
\hline $\begin{array}{l}\text { There are prepared forms documents on collaborating with (referring to) APs in case of supporting the } \\
\text { prevention of employees' diseases exacerbation }\end{array}$ & $2.28(1.21-4.30)$ & $3.63(1.94-6.79)$ \\
\hline
\end{tabular}

Values of odds ratios were adjusted for size of the company occupational physicians belong to (binomial, i.e. whether the number of employees is more than 500 or not).

exerted significant effects that were independent of those exerted by company size.

\section{Discussion}

This is the first report showing that support measures for OPs, such as guidelines including prescribed forms for information exchange and the involvement of occupational health nurses, play important roles in fostering collaboration with APs. More importantly, these measures increased the frequency of collaboration regardless of company size as illustrated in Table 4. These support measures were effective in situations such those involving employees returning to work and follow-up of annual health check-ups. Furthermore, collaboration frequency was more strongly affected by these factors than by the opinions of OPs and APs. The individual demographic characteristics of OPs, including their experience and spe- cialty, were not associated with collaboration frequency. As for the measurement of collaboration frequencies, data in Table 3 were strongly influenced by working hours as OPs because we did not adjust them. It is true that most items regarding environmental factors shown in category III in Table 3 were influenced by working hours as OPs, working type as OPs (full-time or part-time), and company size. On the other hand, most items about OPs' individual background as category I and opinions about collaboration as category II in Table 3 were not associated with these factors since there were no difference in distribution of working hours, working type, and company size between two groups of respondents of Yes or No for corresponding items. In order to standardize of this confounding factor, we adjusted company size when we calculate the adjusted odds ratio in Table 4. One of the main purposes of this research is identifying factors which are determinant for promoting collaboration especially in 
small sized companies. Therefore, we adjusted company size, which has positive relationship with working hours as OPs, and this enabled us to evaluate frequencies of collaboration without this confounding factor. Our findings suggest that the establishment of a supportive company environment for OPs is the most effective approach to encouraging OPs to collaborate with APs.

As shown in Table 2, more than $70 \%$ of OPs strongly agreed that collaboration with APs is a necessity; this was viewed as particularly important for employees returning to work following sick leave for mental health disorders and for preparing for medical emergencies. These data may be explained by the implementation of the Japanese Government's Health Care Policy in 2009, which strongly recommends collaboration between OPs and APs as well as the establishment of rehabilitation institutions to support the return of employees with mental health disorders to work. We found that more than $50 \%$ of respondents strongly believed that cooperation between OPs and APs is important for supporting the return to work of employees with chronic physical diseases who are receiving treatment as well as for preventing the exacerbation of diseases following health check-ups. Although most OPs recognized the value of collaboration with APs, the frequency of collaboration differed depending on the OP's personal characteristics. While the OP's individual background (e.g., years of experience and specialty) was not associated with the frequency of collaboration, both strongly positive opinions toward collaboration and a supportive corporate environment were significantly associated with collaboration, as shown in Tables 3 and 4 . These results suggest that a positive opinion of collaboration is associated with promoting collaboration between OPs and APs, supporting employees with mental health disorders returning to work, and trying to prevent disease exacerbation following annual health check-ups. These findings are in agreement with several other reports showing that educational interventions were effective in promoting collaborative behaviors among physicians ${ }^{5,27,34,36,40)}$. These collaboration between occupational and clinical medicine comprises cooperation between OPs and other categories of physicians such as specialists, general practitioners, and rehabilitation clinicians ${ }^{5,11,23-28)}$. Generally, larger companies have more advanced benefit programs and better systems of occupational healthcare ${ }^{41,42)}$. In order to accurately evaluate the effect of support measures on collaboration, adjustments for company size were performed using a logistic regression model. These analyses showed that the presence of occupational health nurses and guidelines for collaboration including prescribed forms of information exchange were significantly associated with the frequency of collaboration, even after adjusting for company size, as shown in Table 4. Considering that the adjusted odds ratios (aORs) for support measures were greater than those for highly positive opinions on collaboration, communication facilitation tools, which can be used by OPs to communicate with APs, may be more effective than educational tools for promoting the exchange of information. These results highlight the importance of implementing support measures in the occupational health system. Furthermore, when we adjusted for confounding factors in addition to company size, such as the presence of occupational health nurses and guidelines on collaboration, using multiple logistic regression analysis, we found that the adjusted odds ratios (aORs) for the presence of occupational health nurses and guidelines including prescribed forms with regard to collaboration for the purpose of supporting a return to work were 4.4 (95\% CI: $1.0-21)$ and 3.9 (95\% CI: 1.9-8.2), respectively. Similarly, the adjusted odds ratios (aORs) for following up on annual health check-ups were $3.5(0.9-13)$ and 3.3 (1.7-6.1), respectively. The association between the presence of occupational health nurses and health promotion activities at worksites was suggested in a report from Japan ${ }^{41)}$. From the viewpoint of collaboration between workplaces and medical institutions, occupational health nurses play an important role in the cooperative behavior of OPs with APs. From our analysis, occupational health nurses arrange the collaboration such as preparing for information exchange letters or sometimes they accompany employees' visits to APs with letters from OPs, and perhaps write up forms to APs on behalf of OPs (data not shown). These roles of occupational health nurses may be effective in cooperation between OPs and several types of physicians such as specialists and general practitioners in medical institutions or rehabilitation institutions ${ }^{5,11,23-28)}$. As for the presence of prescribed forms of collaboration, it definitely reduces the burden for OPs to write up documents to APs and promote the collaboration behavior. From the facts and considerations above, both occupational health nurses and prescribed forms on collaboration were independent factors associated with increased OP-AP collaboration.

It is important for OPs to obtain medical information directly from APs to plan for an employee's return to work and to refer employees to APs (specialists) to prevent disease exacerbation. However, the workload of OPs has increased, partly due to the introduction of the obligatory Brief Job Stress Questionnaire check-ups in Japan. 
Therefore, efficient and convenient support systems for the exchange of medical information between OPs and APs are required. In our survey, $85.9 \%$ of large companies with at least 200 employees had support systems for employees returning to work, whereas only $64.6 \%$ of smaller companies with fewer than 200 employees had such support systems available. There may be several barriers to the implementation of new occupational health support systems, such as hiring occupational health nurses, which is especially challenging for small companies due to the high costs. On the other hand, the implementation of guidelines including prescribed forms on information exchange is a promising approach to the promotion of collaboration in view of its low cost.

Supervisors must understand employees' health conditions to facilitate the ability of the latter to balance work and disease treatment ${ }^{5}$. Although the exchange of medical information between OPs and APs is useful for employees, some employees may not want anyone to have access to their health information. Therefore, the guidelines published by the Japanese Government ${ }^{6)}$ emphasize that employee agreement is always required for APs and OPs to exchange medical information. Explicit consent (e.g., a signature on documents outlining information exchange) may remove barriers to medical staffs (including APs) who have their activities restricted by confidentiality issues. Additionally, as of 2017, the government healthcare insurance system in Japan does not provide payment to APs for preparing such documents as a Fit Note. Based on our pilot survey of 282 APs who were members of the Tokyo Medical Association, the average ideal rewards for preparing a document (e.g., a Fit Note) was 3,475 yen (data not shown here, prepared for submitting another articles). The provision of appropriate rewards to APs for information exchange could improve the collaborative environment.

The number of cancer survivors is increasing in Japan, and it is important to provide support for these individuals in both workplaces and medical institutions. In medical institutions, the development of positive attitudes and behaviors by APs (oncologists) in relation to collaborating with patients' workplace depended on the availability of support measures ${ }^{5)}$, which was consistent with our results regarding OPs in the workplace. In Japan, the length of the approved sick leave of most employees depends on the company, but most companies guarantee at least 3 to 6 months if they are regular employment, after which more than half of patients with gastric, colon, and genital cancers who want to continue their job can return to the workplace ${ }^{3)}$. For the support of returning-to-work of contractual employment workers, we propose that legal requirement be necessary for the guarantee of the same period sickness absence, which enables OPs to take advantage of support system for collaboration. Based on our results, guidelines including prepared fixed documents are definitely useful for employees who are returning to work with these cancers ${ }^{11)}$. Support measures and collaboration (including with rehabilitation institutions) are also required for stroke survivors ${ }^{4)}$. Moreover, OPs can function as generalists in the workplace, as some physical diseases (e.g., chronic musculoskeletal disorders), including mental disorders $\left.{ }^{43}, 44\right)$, are strongly associated with psychosocial factors, and cancer survivors often experience mental health issues, such as sleep disorders ${ }^{45-47)}$. Supportive measures for OPs, such as guidelines including prescribed documents on collaboration, are required to enable them to care for employees with physical and mental disabilities.

This study has several limitations. First, as this was a cross-sectional study, causal associations could not be determined. Second, respondents may have provided socially desirable opinions. Thus, our responses may reflect a bias toward social desirability. Third, OPs with positive opinions on collaboration may have been more likely to participate in this study. Thus, it is possible that our results overestimate the awareness and frequency of collaboration. However, the factors affecting collaboration were not affected by these biases.

\section{Conclusion}

Although the majority of OPs agreed on the importance of collaboration with employees and APs, the frequency of collaboration varied depending on the supportive measures within the company but not on the individual characteristics of OPs. The presence of support measures, such as occupational health nurses and guidelines including prescribed forms on information exchange and collaboration, plays an important role in fostering a collaborative environment.

\section{Authors' Contributions}

G.M. and R.I.N. planned the research for this study, collected information from previous studies, performed statistical analysis, and drafted the manuscript. M.E. was consulted on the questionnaire items. M.S. arranged the study area and was involved in the recruitment of study 
participants. Y.O. and F.K. advised on data collection, statistical analysis and reviewed the manuscript. K.Y. supervised and provided advice about this study. All authors read and approved the final manuscript.

\section{Conflict of Interest}

None declared.

\section{Acknowledgements}

This study was funded by grants from the Japanese Ministry of Health, Labour and Welfare (Health and Labour Sciences Research Grant (no. H26-28 rousaishippei kenkyuujigyouhi hojyokin (14010101-02) and no. H29 (170401-01)). We thank Dr. Takehisa Matsukawa, Dr. Hiroaki Itoh, Dr. Ayano Kubota for technical assistance, and E. Momma for manuscript preparation. The authors would like to thank all members and participants for help with data collection and their general assistance.

\section{References}

1) Survey on State of Employees' Health performed by The Ministry of Health, Labour and Welfare of Japan (2012) http://www.mhlw.go.jp/toukei/list/h24-46-50.html. Accessed December 2016 (In Japanese).

2) Nomura K, Koizumi A (2016) Strategy against aging society with declining birthrate in Japan. Ind Health 54, 477-9. [Medline] [CrossRef]

3) Endo M, Haruyama Y, Takahashi M, Nishiura C, Kojimahara N, Yamaguchi N (2016) Returning to work after sick leave due to cancer: a 365-day cohort study of Japanese cancer survivors. J Cancer Surviv 10, 320-9. [Medline] [CrossRef]

4) Endo M, Sairenchi T, Kojimahara N, Haruyama Y, Sato Y, Kato R, Yamaguchi N (2016) Sickness absence and return to work among Japanese stroke survivors: a 365-day cohort study. BMJ Open 6, e009682. [Medline] [CrossRef]

5) Wada K, Ohtsu M, Aizawa Y, Tanaka H, Tagaya N, Takahashi M (2012) Awareness and behavior of oncologists and support measures in medical institutions related to ongoing employment of cancer patients in Japan. Jpn J Clin Oncol 42, 295-301. [Medline] [CrossRef]

6) The Ministry of Health, Labour and Welfare (2016) http:// www.mhlw.go.jp/file/06-Seisakujouhou-11200000Roudoukijunkyoku/0000116659.pdf. Accessed December 2016 (In Japanese).

7) Yokokawa H, Fukuda H, Yuasa M, Sanada H, Hisaoka T, Naito T (2016) Association between health literacy and metabolic syndrome or healthy lifestyle characteristics among community-dwelling Japanese people. Diabetol
Metab Syndr 8, 30. [Medline] [CrossRef]

8) Fukuda H, Mizobe M (2017) Impact of nonadherence on complication risks and healthcare costs in patients newlydiagnosed with diabetes. Diabetes Res Clin Pract 123, 55-62. [Medline] [CrossRef]

9) The Japan Diabetes Society. \{Tounyoubyo-tiryo-guide\}, 2016 (In Japanese).

10) Endo M, Muto T, Haruyama $Y$, Yuhara M, Sairenchi T, Kato R (2015) Risk factors of recurrent sickness absence due to depression: a two-year cohort study among Japanese employees. Int Arch Occup Environ Health 88, 75-83. [Medline] [CrossRef]

11) Furuya $Y$, Takahashi M, Tateishi S, Tomita M, Hiraoka K, Shibata Y, Mori K (2016) Survey on information sharing related to the occupational considerations of working cancer patients between occupational physicians and treating physicians. Sangyo Eiseigaku Zasshi 58, 54-62 (In Japanese). [Medline] [CrossRef]

12) Baker BA, Dodd K, Greaves IA, Zheng CJ, Brosseau L, Guidotti T (2007) Occupational medicine physicians in the United States: demographics and core competencies. J Occup Environ Med 49, 388-400. [Medline] [CrossRef]

13) Cloeren M, Gean C, Kesler D, Green-McKenzie J, Taylor M, Upfal M, Hodgson M, Adamo P, Harber P, McLellan R (2014) American College of Occupational and Environmental Medicine's Occupational and Environmental Medicine Competencies-2014: ACOEM OEM Competencies Task Force. J Occup Environ Med 56, e21-40. [Medline] [CrossRef]

14) Persechino B, Fontana L, Buresti G, Rondinone BM, Laurano P, Imbriani M, Iavicoli S (2016) Professional activity, information demands, training and updating needs of occupational medicine physicians in Italy: national survey. Int J Occup Med Environ Health 29, 837-58. [Medline] [CrossRef]

15) Tamminga SJ, Verbeek JH, Bos MM, Fons G, Kitzen JJ, Plaisier PW, Frings-Dresen MH, de Boer AG (2013) Effectiveness of a hospital-based work support intervention for female cancer patients - a multi-centre randomised controlled trial. PLoS One 8, e63271. [Medline] [CrossRef]

16) van der Feltz-Cornelis CM, Hoedeman R, de Jong FJ, Meeuwissen JA, Drewes HW, van der Laan NC, Adèr HJ (2010) Faster return to work after psychiatric consultation for sicklisted employees with common mental disorders compared to care as usual. A randomized clinical trial. Neuropsychiatr Dis Treat 6, 375-85. [Medline] [CrossRef]

17) Vermeulen SJ, Anema JR, Schellart AJ, Knol DL, van Mechelen W, van der Beek AJ (2011) A participatory return-to-work intervention for temporary agency workers and unemployed workers sick-listed due to musculoskeletal disorders: results of a randomized controlled trial. J Occup Rehabil 21, 313-24. [Medline] [CrossRef]

18) Lambeek LC, van Mechelen W, Knol DL, Loisel P, Anema JR (2010) Randomised controlled trial of integrated care to reduce disability from chronic low back pain in working 
and private life. BMJ 340, c1035. [Medline] [CrossRef]

19) Verger $P$, Ménard $C$, Richard JB, Demortière G, Beck F (2014) Collaboration between general practitioners and occupational physicians: a comparison of the results of two national surveys in France. J Occup Environ Med 56, 209-13. [Medline] [CrossRef]

20) Anema JR, Jettinghoff K, Houtman I, Schoemaker CG, Buijs PC, van den Berg R (2006) Medical care of employees long-term sick listed due to mental health problems: a cohort study to describe and compare the care of the occupational physician and the general practitioner. J Occup Rehabil 16, 41-52. [Medline] [CrossRef]

21) Hoedeman R, Krol B, Blankenstein AH, Koopmans PC, Groothoff JW (2010) Sick-listed employees with severe medically unexplained physical symptoms: burden or routine for the occupational health physician? A cross sectional study. BMC Health Serv Res 10, 305. [Medline] [CrossRef]

22) Buijs P, Gunnyeon B, van Weel C (2012) Primary health care: what role for occupational health? Br J Gen Pract 62, 623-4. [Medline] [CrossRef]

23) Persechino B, Fontana L, Buresti G, Rondinone BM, Laurano P, Fortuna G, Valenti A, Iavicoli S (2017) Collaboration of occupational physicians with national health system and general practitioners in Italy. Ind Health 55, 180-91. [Medline] [CrossRef]

24) Beaumont D (2003) Rehabilitation and retention in the workplace - the interaction between general practitioners and occupational health professionals: a consensus statement. Occup Med (Lond) 53, 254-5. [Medline] [CrossRef]

25) Beaumont DG (2003) The interaction between general practitioners and occupational health professionals in relation to rehabilitation for work: a Delphi study. Occup Med (Lond) 53, 249-53. [Medline] [CrossRef]

26) de Buck PD, van Amstel RJ, Buijs PC, Maasen JH, van Dijk FJ, Hazes JM, Vliet Vlieland TP (2002) Communication between Dutch rheumatologists and occupational physicians in the occupational rehabilitation of patients with rheumatic diseases. Ann Rheum Dis 61, 62-5. [Medline] [CrossRef]

27) Moßhammer D, Natanzon I, Manske I, Grutschkowski P, Rieger MA (2014) Cooperation between general practitioners and occupational health physicians in Germany: how can it be optimized? A qualitative study. Int Arch Occup Environ Health 87, 137-46. [CrossRef]

28) Schwarze M, Spallek M, Korallus C, Manecke IA, Teumer F, Wrbitzky R, Gutenbrunner C, Rebe T (2013) Advantages of the JobReha discharge letter: an instrument for improving the communication interface in occupational rehabilitation. Int Arch Occup Environ Health 86, 699708. [Medline] [CrossRef]

29) Department for Work \& Pensions UK 2013: Statement of Fitness for Work. https://www.gov.uk/government/ collections/fit-note. Accessed December 2016.
30) Coole C, Potgieter I, Nouri F, Worthington E, Drummond A (2015) Return-to-work outcomes and usefulness of actual fit notes received by employers. Fam Pract 32, 551-6. [Medline] [CrossRef]

31) Rannard A, Gabbay M, Sen D, Riley R, Britt D (2014) Feasibility trial of GP and case-managed support for workplace sickness absence. Prim Health Care Res Dev 15, 252-61. [Medline] [CrossRef]

32) Gabbay M, Taylor L, Sheppard L, Hillage J, Bambra C, Ford F, Preece R, Taske N, Kelly MP (2011) NICE guidance on long-term sickness and incapacity. Br J Gen Pract 61, e118-24. [Medline] [CrossRef]

33) Coole C, Nouri F, Potgieter I, Watson PJ, Thomson L, Hampton R, Drummond A (2015) Recommendations to facilitate the ideal fit note: are they achievable in practice? BMC Fam Pract 16, 138. [Medline] [CrossRef]

34) Cohen D, Khan S, Marfell N (2016) Fit for work? Evaluation of a workshop for rheumatology teams. Occup Med (Lond) 66, 296-9. [Medline] [CrossRef]

35) Coole C, Drummond A, Watson PJ, Nouri F, Potgieter I. Getting the best from the fit note: investigating the use of the statement of fitness for work. Wigston: Institution of Occupational Safety and Health. www.iosh.co.uk/fitnote. Accessed December 2016.

36) Cohen D, Khan S, Allen J, Sparrow N (2012) Shifting attitudes: the National Education Programme for work and health. Occup Med (Lond) 62, 371-4. [Medline] [CrossRef]

37) Hayashino Y, Suzuki H, Yamazaki K, Goto A, Izumi K, Noda M (2016) A cluster randomized trial on the effect of a multifaceted intervention improved the technical quality of diabetes care by primary care physicians: The Japan Diabetes Outcome Intervention Trial-2 (J-DOIT2). Diabet Med 33, 599-608. [Medline] [CrossRef]

38) Beach J, Watt D (2003) General practitioners and occupational health professionals. BMJ 327, 302-3. [Medline] [CrossRef]

39) Buijs P, van Amstel R, van Dijk F (1999) Dutch occupational physicians and general practitioners wish to improve cooperation. Occup Environ Med 56, 709-13. [Medline] [CrossRef]

40) Nauta N, Weel A, Overzier P, von Grumbkow J (2006) The effects of a joint vocational training programme for general practitioner and occupational health trainees. Med Educ 40, 980-6. [Medline] [CrossRef]

41) Kanamori S, Kai Y, Kawamata K, Kusumoto M, Takamiya T, Ohya Y, Odagiri Y, Fukushima N, Inoue S (2015) [The association between the presence of occupational health nurses at Japanese worksites and health promotion activities]. Sangyo Eiseigaku Zasshi 57, 297-305 (In Japanese). [Medline] [CrossRef]

42) Inoue A, Kawakami N, Tsuchiya M, Sakurai K, Hashimoto H (2010) Association of occupation, employment contract, and company size with mental health in a national representative sample of employees in Japan. J Occup 
Health 52, 227-40. [Medline] [CrossRef]

43) Matsudaira K, Kawaguchi M, Isomura T, Inuzuka K, Koga T, Miyoshi K, Konishi H (2015) Assessment of psychosocial risk factors for the development of nonspecific chronic disabling low back pain in Japanese workers-findings from the Japan Epidemiological Research of Occupation-related Back Pain (JOB) study. Ind Health 53, 368-77. [Medline] [CrossRef]

44) Sawada T, Matsudaira K, Muto Y, Koga T, Takahashi M (2016) Potential risk factors for onset of severe neck and shoulder discomfort (Katakori) in urban Japanese workers. Ind Health 54, 230-6. [Medline] [CrossRef]
45) Savard J, Simard S, Blanchet J, Ivers H, Morin CM (2001) Prevalence, clinical characteristics, and risk factors for insomnia in the context of breast cancer. Sleep 24, 583-90. [Medline] [CrossRef]

46) Fiorentino L, Ancoli-Israel S (2007) Sleep dysfunction in patients with cancer. Curr Treat Options Neurol 9, 337-46. [Medline] [CrossRef]

47) Palesh O, Aldridge-Gerry A, Zeitzer JM, Koopman C, Neri E, Giese-Davis J, Jo B, Kraemer H, Nouriani B, Spiegel D (2014) Actigraphy-measured sleep disruption as a predictor of survival among women with advanced breast cancer. Sleep 37, 837-42. [Medline] [CrossRef] 